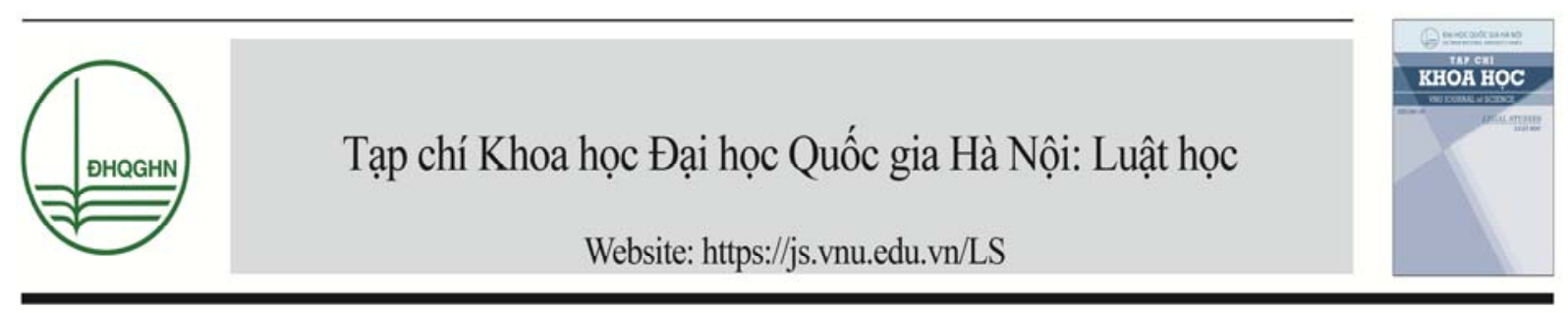

\title{
Bảo hộ chương trình máy tính theo pháp luật Việt Nam: Thực tiễn và thách thức ${ }^{1}$
}

\author{
Trần Kiên ${ }^{*}$ \\ Khoa Luật, Đại học Quốc gia Hà Nội, 144 Xuân Thủy, Cầu Giấy, Hà Nội, Việt Nam \\ Ngày nhận 12 tháng 10 năm 2018 \\ Chỉnh sửa ngày 09 tháng 11 năm 2018; Chấp nhận đăng ngày 24 tháng 12 năm 2018
}

Tóm tắt: Bài viết đi sâu phân tích các quy định của pháp luật Việt Nam về bảo hộ chương trình máy tính. Bài viết chỉ ra rằng, học tập kinh nghiệm và thực tiễn lập pháp quốc tế Việt Nam đã lựa chọn cách thức bảo hộ chương trình máy tính với tư cách là một đối tượng của quyền tác giả. Tuy nhiên, cách thức bảo hộ này cũng có những hạn chế, nhược điểm nhất định khiến cho việc bảo hộ không có được kết quả như mong đợi. Các thách thức đó đặt ra yêu cầu cần phải sửa đổi, bổ sung pháp luật hiện hành hoặc là tìm kiếm một mô hình, cách thức bảo hộ khác, phù hợp hơn, hiệu quả hơn để bảo vệ chương trình máy tính trong pháp luật Việt Nam.

Tù khóa: Chương trình máy tính, quyền tác giả, sáng chế, hợp đồng, luật sở hữu trí tuệ.

\section{Chương trình máy tính và bảo hộ chương trình máy tính trên thế giới}

\subsection{Chuoong trình máy tính}

Chương tình máy tính (computer program) hay phần mềm máy tính (software) là một tập hợp các chỉ thị hoặc các câu lệnh được viết bằng một hoặc nhiều ngôn ngữ lập trình theo một trật tự xác định ra để chỉ dẫn máy tính thực hiện một nhiệm vụ nhất định [1].

Luật sở hữu trí tuệ Việt Nam cũng định nghĩa chương trình máy tính là tập hợp các chỉ

\footnotetext{
*ĐT.: 84-24-37547511.

Email: trankien@vnu.edu.vn https://doi.org/10.25073/2588-1167/vnuls.4178

${ }^{1}$ Nghiên cứu này được tài trợ bởi Quỹ Phát triển khoa học và công nghệ Quốc gia (NAFOSTED) trong đề tài mã số 505.01-2017.02.
}

dẫn được thể hiện dưới dạng các mã lệnh, các mã, lược đồ hoặc bất kì dạng nào khác, khi gắn vào một phương tiện mà máy tính đọc được, có khả năng làm cho máy tính thực hiện được một công việc hoặc đạt được một kết quả cụ thể .

Bằng định nghĩa này, Việt Nam thuộc vào một trong số các ít nước trên thế giới có một định nghĩa chính thức về chương trình máy tính [2]. Trung Quốc cũng có một định nghĩa chính thức về chương trình máy tính, và định nghĩa này khá giống với định nghĩa trong luật Việt $\mathrm{Nam}^{2}$. Qua các định nghĩa nêu trên cho thấy, dù

\footnotetext{
${ }^{1}$ Luật Sở hữu trí tuệ 2005 (sửa đổi bổ sung 2009) Điều 22 Khoản 1.

${ }^{2}$ Quy định về bảo hộ chương trình máy tính ban hành theo Nghị định số 339 của Quốc vụ viện Cộng hòa nhân dân Trung Hoa ngày 20 tháng 12 năm 2001. Điều 3 khoản 1: "chương trình máy tính có nghĩa là tập hợp các chỉ dẫn mã
} 51 
vẫn chưa có một khái niệm phổ biến được sử dụng rộng rãi nhưng các tính chất căn bản của chương trình máy tính đã được chấp nhận cả về khía cạnh kĩ thuật và pháp lí.

Cho dù những mô hình chương trình máy tính sơ khai đầu tiên đã được biết đến và phát minh từ những năm đầu thế kỉ 19 , nhưng phải đến năm 1936 Alan Turing, thiên tài toán học người Anh mới giới thiệu đến thế giới chiếc máy tính đúng nghĩa đầu tiên vận hành dựa trên các chương trình máy tính. Kể từ đó, công nghiệp máy tính và chương trình máy tính đã có những sự phát triển mạnh mẽ, đóng vai trò hạt nhân của cuộc cách mạng công nghệ, kĩ thuật số. Đặc biệt, sự ra đời của máy tính cá nhân (personal computer) và sau đó là các thiết bị di động cầm tay thông minh (smart phones) đã khiến cho chương trình máy tính càng ngày càng đóng vai trò trung tâm, thiết yếu không chỉ trong các hoạt động kinh tế, tri thức, công nghệ mà còn cả trong cuộc sống cá nhân của mỗi người [3].

Thống kê cho thấy ngành công nghệ thông tin toàn cầu (information technology) có giá trị 3.8 ngàn tỉ USD [4], trong đó ngành công nghiệp phần mềm hay chương trình máy tính đóng góp 407.3 tỉ USD [5]. Ở Việt Nam, doanh thu ngành phần mềm và công nghệ thông tin đã tăng gấp rưỡi trong thời gian 5 năm từ 2010 đến 2015, đạt giá trị hơn 3 tỉ USD. Trong đó, phần mềm hay chương trình máy tính đóng góp đến 1.6 tỉ USD [6].

Điều này cho thấy vai trò và giá trị kinh tế to lớn của công nghệ thông tin nói chung và chương trình máy tính nói riêng đối với nền kinh tế và xã hội của các quốc gia cũng như của toàn thế giới. Nhưng cũng chính vì thế, chương trình máy tính cũng trở thành đối tượng bị sao chép, sử dụng trái phép tràn lan trên toàn thế giới. Có đến $57 \%$ số người sử dụng máy tính trên thế giới thừa nhận họ có sử dụng các phần mềm máy tính bị sao chép bất hợp pháp [7].

thông tin ví dụ như máy tính, hoặc là các dòng chỉ dẫn biểu tượng hoặc các dòng tuyên bố biểu tượng có thể được chuyển đổi tự động thành các chỉ dẫn mã hóa có thể hoàn thành được các kết quả như mong đợi; mã nguồn và mã máy của máy tính được xem là một tác phẩm.
Giá trị của các phần mềm máy tính bị sao chép trái phép đó lên tới 63.4 tỉ USD chỉ tính riêng vào năm 2011 [8]. Tỉ lệ sao chép và sử dụng trái phép phần mềm máy tính ở Việt Nam lên đến $81 \%$, với giá trị thiệt hại là 395 triệu USD [9].

Do giá trị kinh tế to lớn và đứng trước tình hình xâm phạm nêu trên, câu hỏi về việc bảo hộ chương trình máy tính đã trở thành trọng tâm của hầu hết các quốc gia và nhiều tổ chức quốc tế quan trọng trên thế giới. Tuy nhiên, các quốc gia khác nhau lại lựa chọn các mô hình bảo hộ pháp lí khác nhau đối với chương trình máy tính, phụ thuộc vào cách tiếp cận và hệ thống pháp luật hiện hành.

\subsection{Bảo hộ chuơng trình máy tính trên thế giới}

Từ góc độ thực tiễn, các quy định pháp luật bảo hộ chương trình máy tính cũng mới chỉ được ban hành thời gian gần đây. WIPO mới chỉ bắt đầu nghiên cứu về cơ chế bảo hộ pháp lí đối với phần mềm máy tính từ năm 1970 [10]. Ngay tại châu Âu, nơi chương trình máy tính nhận được sự quan tâm mạnh mẽ của các thiết chế chung của châu Âu thì vào thời điểm năm 1991 cũng chỉ có 7 trên 12 quốc gia thành viên Cộng đồng châu Âu là có các quy định về bảo hộ chương trình máy tính [11]. Từ góc độ luật so sánh và thực tiễn pháp luật thế giới, có ba mô hình bảo hộ pháp lí đối với chương trình máy tính, đó là: sui generis (quyền đặc biệt); bảo hộ bằng cơ chế quyền tác giả; và bảo hộ theo các quy định về sáng chế.

\section{a) Bảo hộ theo co chế riêng (sui generis rights)}

Cơ chế pháp lí đầu tiên được đề xuất để bảo vệ chương trình máy tính là do chính WIPO đề xuất từ những năm 1970. Theo đó, các quốc gia nên ban hành các quy định riêng, đặc thù, độc lập với các cơ chế khác để bảo vệ chương trình máy tính. Các quy định này thiết lập nên các quyền đặc biệt (sui generis rights) đối với chương trình máy tính [12 - 14]. Tuy nhiên, các đề xuất này không nhận được sự ủng hộ của các quốc gia thành viên dù rằng đôi lúc vẫn được không ít học giả đề xuất [15]. 


\section{b) Bảo hộ bằng các quy định về quyền tác giả (copyright)}

Cũng tại thời điểm WIPO nghiên cứu về cơ chế pháp lí bảo hộ đối với chương trình máy tính, có 5 quốc gia trên thế giới đã áp dụng các quy định về bản quyền để bảo hộ chương trình máy tính ${ }^{3}$. Dựa trên kinh nghiệm của các quốc gia này, vào tháng 02 năm 1985 , WIPO và UNESCO đã thành lập một nhóm chuyên gia chung về các khía cạnh bản quyền của chương trình máy tính. Và nhóm chuyên gia này đã đề xuất áp dụng cơ chế bảo hộ bản quyền đối với chương trình máy tính ${ }^{4}$. Từ khuyến nghị của WIPO và UNESCO, các quốc gia khác đã bắt đầu áp dụng cơ chế bảo hộ quyền tác giả. Tuy nhiên, động lực thực sự thúc đẩy việc áp dụng các quy định về quyền tác giả đối với chương trình máy tính bắt nguồn từ các điều ước quốc tế trong lĩnh vực quyền sở hữu trí tuệ. Năm 1991, Cộng đồng kinh tế châu Âu ban hành Chỉ thị 91/250/EEC về bảo hộ pháp lí đối với chương trình máy tính. Trong đó, EEC yêu cầu tất cả các quốc gia thành viên của Cộng đồng kinh tế châu Âu phải nội luật hóa Chỉ thị 91 và ban hành các quy định pháp luật trong nước để bảo vệ chương trình máy tính bằng các quyền tác giảs. Tiếp sau đó, Hiệp định TRIPS (1994) cũng yêu cầu tất cả các quốc gia thành viên của WTO phải bảo hộ chương trình máy tính với tư cách là một tác phẩm văn học theo Công ước Berne về bảo hộ tác phẩm văn học nghệ thuật (1971) [16]. Tiểp bước hai điều ước quốc tế quan trọng nêu trên, Công ước WIPO về bản quyền - WIPO Copyright Treaty (1996) cũng ràng buộc các quốc gia thành viên phải bảo hộ chương trình máy tính dưới hình thức là các tác phẩm văn học theo Điều 2 của Công ước Berne [17]. Kết quả là cho đến nay tuyệt đại đa số các

\footnotetext{
3 quốc gia này là the Philippines, the United States of America, Hungary, Australia and India. Xem WIPO, International IP Protection of Software, tai http://www.wipo.int/edocs/mdocs/copyright/en/wipo_ip_c m_07/wipo_ip_cm_07_www_82573.doc.

${ }^{4}$ Ibid.

${ }^{5}$ Chỉ thị này hiện nay đã bị thay thế bằng Chỉ thị Directive 2009/24/EC of the European Parliament and of the Council of 23 April 2009 on the legal protection of computer programs.
}

quốc gia trên thế giới, đặc biệt là các quốc gia thuộc liên minh châu Âu, các quốc gia thành viên của WTO và WIPO đều bảo hộ chương trình máy tính bằng các quy định về quyền tác giả với những khác biệt nhất định [18].

\section{c) Bảo hộ bằng các quy định về sáng chế}

Cơ chế bảo hộ pháp lí phổ biến thứ ba đối với chương trình máy tính là thông qua các quy định về sáng chế. Hay nói cách khác, chương trình máy tính có thể được xem là một giải pháp kĩ thuật. Việc này được thực hiện chủ yếu thông qua án lệ và nộp đơn xin bảo hộ sáng chế đối với một số chương trình máy tính nhất định. Bằng sáng chế đầu tiên được cấp cho một chương trình máy tính là ở Vương quốc Anh vào năm 1966 [19]. Ở Mỹ, án lệ đã chấp nhận việc cấp bằng sáng chế cho các chương trình máy tính gắn liền với một máy móc hoặc các kết cấu cụ thể hoặc khi hoạt động có khả năng thay đổi các chất liệu hoặc hạt vật chất đến các trạng thái khác [20]. Theo quy định của Hiệp định TRIPS, chương trình máy tính không được đề cập minh thị là đối tượng có thể được bảo hộ sáng chế nhưng cũng không bị loại trừ [21]. Điều này đã dẫn đến nhưng tranh cãi lớn về khả năng bảo hộ sáng chế đối với chương trình máy tính [22]. Công ước châu Âu về bằng sáng chế tuy có quy định cụ thể rằng các chương trình máy tính (programs for computers) không phải là đối tượng có thể được cấp bằng sáng chế [23]. Tuy nhiên, quy định này không phải là không có tranh cãi và vẫn có các chương trình máy tính có thể được cấp bằng sáng chế theo Công ước châu Âu. Hiệp ước hợp tác về sáng chế (Patent Cooperation Treaty (1970) cho phép các cơ quan cấp bằng sáng chế của các quốc gia thành viên từ chối tìm kiếm và thẩm định các đơn yêu cầu cấp bằng sáng chế có đối tượng là chương trình máy tính [24]. Có luật gia Việt Nam đã giải thích điều này có nghĩa là Hiệp ước cho phép loại trừ chương trình máy tính được cấp sáng chế [15, tr.33-42].

Cuối cùng, tuy không thật sự phổ biến và được biết đến rộng rãi, án lệ Mỹ đã mở rộng phạm vi bảo hộ của bí mật thương mại đối với thông tin nằm trong mã nguồn của chương 
trình máy tính [25]. Ngoài ra, theo Giáo sư Nguyễn Ngọc Xuân Thảo, trade dress - hình ảnh thương mại cũng có thể là một ứng cử viên lí tưởng được áp dụng để bảo hộ chương trình máy tính $[18$, tr.409].

\section{Pháp luật Việt Nam về bảo hộ chương trình máy tính}

Tại Việt Nam, pháp luật về bảo hộ chương trình máy tính đã trải qua quá trình phát triển không dài nhưng khá mạnh mẽ theo đúng sự phát triển của pháp luật thế giới, bao gồm cả các tranh cãi và thách thức. Kể từ những năm 1980, khi Việt Nam bắt ban hành nhiều quy định khác nhau về bảo hộ các quyền sở hữu trí tuệ thì chương trình máy tính đã luôn hiện diện như là một đối tượng quan trọng. Một phần của sự tích cực đó bắt nguồn từ việc Việt Nam kí kết nhiều hiệp định song phương và đa phương trong đó cam kết bảo hộ phần mềm máy tính trong pháp luật Việt Nam, đặc biệt với tư cách là một đối tượng của quyền tác giả. Tuy nhiên, cũng tồn tại các thực tiễn cho thấy Việt Nam bỏ ngỏ khả năng áp dụng các biện pháp bảo hộ khác, đặc biệt là thông qua bằng sáng chế.

\subsection{Bảo hộ chuơng trình máy tính theo luật về quyền tác giả của Việt Nam}

Đầu tiên, có thể đưa ra một nhận định tổng quan rằng Việt Nam đã luôn nhất quán trong việc lựa chọn mô hình bảo hộ chương trình máy tính là một đối tượng của quyền tác giả.

Pháp lệnh bảo hộ quyền tác giả 1994 minh thị quy định phần mềm máy tính là một loại hình tác phẩm văn học, nghệ thuật, khoa học được bảo hộ quyền tác giả ${ }^{6}$. Ở đây, Pháp lệnh sử dụng thuật ngữ phần mềm máy tính chứ không phải chương trình máy tính và giải thích rằng: Phần mềm máy tính là một hoặc một nhóm chương trình được biểu hiện dưới dạng chuỗi lệnh viết theo một ngôn ngữ lập trình nào đó và các tệp dự liệu có liên quan, chỉ dẫn cho

\footnotetext{
${ }^{6}$ Pháp lệnh bảo hộ quyền tác giả 1994, Điều 4 Khoản 9.
}

máy tính hoặc hệ thông tin học biết phải làm gì để thực hiện nhiệm vụ đã được đề ra. Phần mềm máy tính có thể được cài đặt ngay trong máy tính hoặc được lưu trữ ở ngoài máy tính dưới các hình thức khác nhau như văn bản, đĩa từ, đĩa quang ${ }^{7}$. Với định nghĩa này, dường như nhà làm luật đánh đồng phần mềm máy tính với chương trình máy tính. Bộ luật dân sự 1995 tiếp tục sử dụng thuật ngữ này và quy định phần mềm máy tính là một tác phẩm được bảo hộ quyền tác giå ${ }^{8}$. Tuy nhiên, Nghị định $76-\mathrm{CP}$ năm 1996 hướng dẫn thi hành một số điều về quyền tác giả lại định nghĩa phần mềm máy tính gồm chương trình máy tính, tài liệu mô tả chương trình, tài liệu hỗ trợ, cơ sở dữ liệu? Theo định nghĩa này thì khái niệm phần mềm máy tính rộng hơn chương trình máy tính. Và đặc biệt quan trọng là bao gồm cả một đối tượng đặc biệt là cơ sở dữ liệu, một đối tượng chưa được thừa nhận một cách chính thức là tác phẩm độc lập được bảo hộ quyền tác giả tại thời điểm đó.

Với cách quy định này, dường như nhà làm luật đã mở rộng phạm vi bảo hộ quyền tác giả đến cả các tài liệu hỗ trợ, và cơ sở dữ liệu thông qua khái niệm phần mềm máy tính, dù trên thực tế cơ sở dữ liệu và chương trình máy tính là hai khái niệm độc lập với nhau [15, tr.33-42]. Có lẽ hiểu ra sự sai sót này nên trong một quy định khác, cơ sở dữ liệu được bỏ ra khỏi khái niệm phần mềm máy tính, chỉ còn chương trình, tài liệu mô tả chương trình, tài liệu hỗ trợ, nội dung thông tin số hóa ${ }^{10}$. Tuy nhiên, với tư cách là một Quyết định của Thủ tướng thì quy định này được coi là có hiệu lực thấp hơn và không thể bác bỏ quy định trong Nghị định 76-CP. Do đó, có thể nói rằng trong giai đoạn 1995 - 2005, phần mềm máy tính bao gồm cả chương trình

\footnotetext{
${ }^{7}$ Ibid, Điều 9 Khoản 2.

${ }^{8}$ Bộ luật dân sự 1995 Điều 747 Khoản 1 điểm o.

${ }^{9}$ Nghị định số 76-CP ngày 29/11/1996 hướng dẫn thi hành một số quy định về quyền tác giả trong Bộ luật dân sự. Điều 4 Khoản 14.

${ }^{10}$ Quyết định 128/2000/QĐ-TTg Về một số chính sách và biện pháp khuyến khích đầu tư và phát triển công nghiệp phần mềm, Điểu 2 Khoản 1.
} 
máy tính và cơ sở dữ liệu. Và hai đối tượng này đều được bảo hộ quyền tác giả.

Dường như hiểu được sự rắc rối này nên $\mathrm{B}$ ộ luật dân sự 2005 đã thay đổi và sử dụng khái niệm chương trình máy tính ${ }^{11}$. Dựa trên các quy định chung của BLDS 2005, Luật Sở hữu trí tuệ (SHTT) 2005 (được sửa đồi bổ sung 2009) đã sử dụng thuật ngữ chương trình máy tính thay vì phần mềm máy tính đồng thời tách sưu tập dữ liệu thành đối tượng riêng biệt cũng được bảo hộ quyền tác giả ${ }^{12}$. Luật SHTT 2005 cũng đưa ra định nghĩa chính thức về chương trình máy tính là: Chương trình máy tính là tập hợp các chỉ dẫn được thể hiện dưới dạng các lệnh, các mã, lược đồ hoặc bất kì dạng nào khác, khi gắn vào một phương tiện mà máy tính đọc được, có khả năng làm cho máy tính thực hiện được một công việc hoặc đạt được một kết quả cụ thể ${ }^{13}$. Cơ chế bảo hộ quyền tác giả đối với chương trình máy tính theo pháp luật Việt Nam có một số đặc điểm chính như sau.

a) Điều kiện bảo hộ quyền tác giả đối với chuoong trình máy tính

Theo quy định của pháp luật Việt Nam, chương trình máy tính được xem là một tác phẩm văn học ${ }^{14}$. Để được xem là một tác phẩm được bảo hộ thì tác phẩm đó phải do tác giả trực tiếp sáng tạo bằng lao động trí tuệ của mình mà không sao chép từ tác phẩm của người khác ${ }^{15}$. Tuy chưa có giải thích rõ ràng về tiêu chí này trong luật, các luật gia Việt Nam cho rằng tác phẩm được bảo hộ phải có tính nguyên gốc, tức là không sao chép tác phẩm khác [26]. Và sáng tạo là việc sử dụng sức lao động và khả năng suy xét để tạo ra tác phẩm [26, tr.56]. Sự sáng tạo, như thế, không có nghĩa rằng tác phẩm phải có tính mới mà chỉ cần có tính nguyên gốc. Hai chương trình máy tính có thể giống hệt nhau nhưng vẫn cũng được bảo hộ nếu như tác giả của hai chương trình đó đã sáng

\footnotetext{
${ }^{11}$ Bộ luật dân sự 2005, Điều 738 Khoản 3 điểm đ, Điều 755 Khoản 1.

${ }^{12}$ Luật sở hữu trí tuệ 2005, Điều 14 Khoản 1 điểm m.

${ }^{13}$ Ibid, Điều 22 Khoản 1.

${ }^{14}$ Ibid, Điều 22 Khoản 1 .

${ }^{15}$ Luật sở hữu trí tuệ 2005, Điều 14 Khoản 3.
}

tạo ra chúng một cách hoàn toàn độc lập, không sao chép của nhau. Như vậy, có thể thấy yêu cầu về mức độ sáng tạo đối với tác phẩm nói chung và chương trình máy tính nói riêng theo pháp luật Việt Nam là không cao. Chương trình máy tính không nhất thiết phải đáp ứng các yêu cầu đặc biệt về mức độ sáng tạo, sự phức tạp, cao siêu thì mới được bảo hộ. Ngoài ra, tác phẩm để được bảo hộ còn phải được định hình dưới một hình thức vật chất nhất định, bao gồm cả hình thức thông điệp dữ liệu thông qua phương tiện điện tử. ${ }^{16}$ Theo cơ chế bảo hộ tự động, quyền tác giả đối với chương trình máy tính phát sinh kể từ khi chương trình được định hình dưới một hình thức vật chất nhất định mà không cần thềm bất cứ điều kiện nào khác, kể cả đăng ký. Phạm vi bảo hộ đối với chương trình máy tính bao gồm cả mã nguồn và mã máy. ${ }^{17}$

b) Chủ thể quyền tác giả đối với chuơng trình máy tính

Đối với tác phẩm nói chung và chương trình máy tính nói riêng, luật Việt Nam phân biệt rõ hai chủ thể là tác giả và chủ sở hữu quyền tác giả. Trước hết, luật Việt Nam quy định tác giả là người trực tiếp sáng tạo ra một phần hoặc toàn bộ tác phẩm văn học, nghệ thuật và khoa học bao gồm: 1) Cá nhân Việt Nam có tác phẩm được bảo hộ quyền tác giả; 2) Cá nhân nước ngoài có tác phẩm được sáng tạo và thể hiện dưới hình thức vật chất nhất định tại Việt Nam; 3) Cá nhân nước ngoài có tác phẩm được công bố lần đầu tiên tại Việt Nam; 4) Cá nhân nước ngoài có tác phẩm được bảo hộ tại Việt Nam theo Điều ước quốc tế về quyền tác giả mà Việt Nam là thành viên ${ }^{18}$. Luật viết không định rõ thế nào là cá nhân Việt Nam. Nhưng có thể hiểu đó là những người có quốc tịch Việt Nam.

\footnotetext{
${ }^{16}$ Luật sở hữu trí tuệ 2005, Điều 6 Khoản 1. Bộ luật dân sự 2015 Điều 119 Khoản 1.Định hình là sự biểu hiện bằng chữ viết, các ký tự khác, đường nét, hình khối, bố cục, màu sắc, âm thanh, hình ảnh hoặc sự tái hiện âm thanh, hình ảnh dưới dạng vật chất nhất định để từ đó có thể nhận biết, sao chép hoặc truyền đạt theo Nghị định số 3198/VBHN-BVHTTDL ngày 03 tháng 09 năm 2013, Điều 4 Khoản 5.

${ }^{17}$ Luật sở hữu trí tuệ 2005, Điều 22 Khoản 1.

${ }^{18}$ Nghị định số 3198/VBHN-BVHTTDL ngày 03 tháng 09 năm 2013, Điều 8 Khoản 1.
} 
Cá nhân nước ngoài có thể là người có quốc tịch nước ngoài hoặc người không có quốc tịch. Để chương trình máy tính của họ được pháp luật Việt Nam bảo hộ thì họ phải công bố chương trình máy tính của họ ở Việt Nam đầu tiên hoặc được công bố đồng thời tại Việt Nam trong thời hạn ba mươi ngày, kể từ ngày tác phẩm đó được công bố lần đầu tiên ở nước khác ${ }^{19}$.

Chủ sở hữu quyền tác giả là tổ chức, cá nhân nắm giữ một, hoặc một số hoặc toàn bộ các quyền tài sản quy định trong luật sở hữu trí tuệ ${ }^{20}$. Chủ sở hữu quyền tác giả có thể đồng thời là tác giả hoặc một người khác, những người giao nhiệm vụ cho tác giả hoặc giao kết hợp đồng sáng tạo chương trình máy tính với tác giả. Chủ sở hữu quyền tác giả đối với chương trình máy tính cũng có thể là người được tác giả chuyển giao quyền tác giả hoặc được thừa kế quyền tác giả ${ }^{21}$.

\section{c) Nội dung quyền tác giả đối với chuoong trình máy tính}

Quyền tác giả đối với chương trình máy tính được pháp luật bảo hộ bao gồm quyền nhân thân và quyền tài sản ${ }^{22}$. Quyền nhân thân là những quyền dân sự gắn liền với mỗi cá nhân, không thể chuyển giao cho người khác, trừ trường hợp luật có quy định khác ${ }^{23}$. Quyền nhân thân còn được phân loại thành quyền nhân thân gắn với tài sản và quyền nhân thân không gắn với tài sản $^{24}$. Đối lập với quyền nhân thân, quyền tài sản là quyền trị giá được bằng tiền ${ }^{25}$.

Các quyền nhân thân đối với chương trình máy tính được pháp luật bảo hộ gồm các quyền: 1) Đặt tên cho tác phẩm; 2) Đứng tên thật hoặc bút danh trên tác phẩm; được nêu tên thật hoặc bút danh khi tác phẩm được công bố, sử dụng; 3) Công bố tác phẩm hoặc cho phép người khác công bố tác phẩm; 4) Bảo vệ sự toàn vẹn của tác phẩm, không cho người khác sửa chữa, cắt

\footnotetext{
${ }^{19}$ Luật sở hữu trí tuệ 2005, Điều 13 Khoản 2.

${ }^{20}$ Luật sở hữu trí tuệ 2005, Điều 36.

${ }^{21}$ Luật sở hữu trí tuệ 2005, Điều $37-41$.

${ }^{22}$ Luật sở hữu trí tuệ 2005, Điều 19, 20.

${ }^{23}$ Bộ luật dân sự 2015, Điều 25.

${ }^{24}$ Bộ luật dân sự 2015, Điều 17 Khoản 1.

${ }^{25}$ Bộ luật dân sự 2015, Điều 115.
}

xén hoặc xuyên tạc tác phẩm dưới bất kì hình thức nào gây phương hại đến danh dự và uy tín của tác giả ${ }^{26}$. Tuy là các quyền nhân thân không gắn với tài sản, nhưng luật Việt Nam lại cho phép tác giả và tổ chức, cá nhân đầu tư tài chính và cơ sở vật chất - kĩ thuật để sáng tạo chương trình máy tính và tác giả chương trình máy tính có thể thỏa thuận khi ký hợp đồng sáng tạo về quyền đặt tên chương trình máy tính và về việc chỉnh sửa, nâng cấp chương trình máy tính ${ }^{27}$.

Các quyền tài sản đối với chương trình máy tính bao gồm: 1) Làm tác phẩm phái sinh; 2) Biểu diễn tác phẩm trước công chúng; 3) Sao chép tác phẩm; 4) Phân phối, nhập khâuu bản gốc hoặc bản sao tác phẩm; 5) Truyền đạt tác phẩm đến công chúng bằng phương tiện hữu tuyến, vô tuyến, mạng thông tin điện tử hoặc bất kì phương tiện kĩ thuật nào khác; 6) Cho thuê bản gốc hoặc bản sao tác phẩm điện ảnh, chương trình máy tính. Chúng ta nhận thấy trong số 6 quyền tài sản thì quyền thứ 6 , quyền cho thuê bản gốc hoặc bản sao là quyền đặc biệt, dành riêng cho đối tượng là chương trình máy tính và tác phẩm điện ảnh. Luật cũng nhấn mạnh, các quyền tài sản này độc quyền do tác giả, chủ sở hữu quyền tác giả thực hiện hoặc cho phép người khác thực hiện ${ }^{28}$. Dường như trong quan điểm của nhà làm luật Việt Nam quyền tác giả không chỉ là một quyền thụ động, tiêu cực (negative rights) cho phép người khác được làm gì với chương trình máy tính của mình, mà còn là một quyền chủ động, tích cực (positive rights) [27, 28].

d) Thời hạn bảo hộ quyền tác giả đối với chuoong trình máy tính

Pháp luật Việt Nam bảo hộ vô thời hạn các quyền nhân thân của tác giả, trừ quyền công bố ${ }^{29}$. Đối với quyền công bố và các quyền tài sản khác thì thời hạn bảo hộ quyền tác giả là suốt cuộc đời tác giả và năm mươi năm tiếp

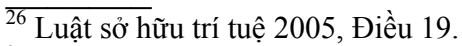

${ }^{27}$ Nghị định số 3198/VBHN-BVHTTDL ngày 03 tháng 09 năm 2013, Điều 19a Khoản 1.

${ }^{28}$ Luật sở hữu trí tuệ 2005, Điều 20 Khoản 2.

${ }^{29}$ Luật sở hữu trí tuệ 2005, Điều 27 Khoản 1.
} 
theo năm tác giả chết; trường hợp tác phẩm có đồng tác giả thì thời hạn bảo hộ chấm dứt vào năm thứ năm mươi sau năm đồng tác giả cuối cùng chết ${ }^{30}$. Giả sử chương trình máy tính bị khuyết danh, tức là không xác định được tác giả là ai thì thời hạn bảo hộ là bảy mươi lăm năm, kể từ khi tác phẩm được công bố lần đầu tiên. Hoặc khi các thông tin về tác giả xuất hiện thì thời hạn bảo hộ được tính theo thời hạn bảo hộ quyền tài sản thông thường ${ }^{31}$.

\section{e) Hành vi sủ dụng hạn chế}

Để cân bằng lợi ích giữa tác giả, chủ sở hữu quyền tác giả và xã hội nói chung, luật Việt Nam cũng dự liệu các trường hợp sử dụng chương trình máy tính hợp lí, công bằng hay còn gọi là các trường hợp sử dụng không phải xin phép, trả thù lao. Theo quy định của pháp luật Việt Nam, xã hội nói chung được thực hiện các hành vi sau đối với chương trình máy tính mà không cần phải xin phép, không phải trả tiền nhuận bút, thù lao:

1) Trích dẫn hợp lí tác phẩm mà không làm sai ý tác giả để bình luận hoặc minh họa trong tác phẩm của mình;

2) Trích dẫn tác phẩm mà không làm sai ý tác giả để viết báo, dùng trong ấn phẩm định kì, trong chương trình phát thanh, truyền hình, phim tài liệu;

3) Trích dẫn tác phẩm để giảng dạy trong nhà trường mà không làm sai ý tác giả, không nhằm mục đích thương mại;

4) Chuyển tác phẩm sang chữ nổi hoặc ngôn ngữ khác cho người khiếm thị;

5) Nhập khẩu bản sao tác phẩm của người khác để sử dụng riêng ${ }^{32}$.

Có thể nhận thấy, hành vi sử dụng hạn chế quan trọng nhất đã bị loại trừ đối với chương trình máy tính, đó là hành vi sao chép một bản nhằm mục đích nghiên cứu khoa học, giảng dạy cá nhân theo Điều 25 Khoản 1 điểm a Luật SHTT 2005. Để bù đắp cho thiếu sót này, Nghị

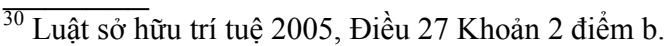

${ }^{31}$ Luật sở hữu trí tuệ 2005, Điều 27 Khoản 2 điểm a.

${ }^{32}$ Luật sở hữu trí tuệ 2005, Điều 25 Khoản 1, 3.
}

định hướng dẫn thi hành Luật SHTT đã bổ sung quy định về việc Tổ chức, cá nhân có quyền sử dụng hợp pháp bản sao chương trình máy tính có thể làm không quá một bản sao dự phòng, để thay thế khi bản sao đó bị mất, bị hư hỏng hoặc không thể sử dụng được ${ }^{33}$. Ngoài ra, luật cũng hạn chế quyền cho thuê bản gốc hoặc bản sao chương trình máy tính khi bản thân chương trình đó không phải là đối tượng chủ yếu để cho thuê như chương trình máy tính gắn với việc vận hành bình thường các loại phương tiện giao thông cũng như các máy móc, thiết bị kĩ thuật khác ${ }^{34}$. Nghị định hướng dẫn thi hành còn làm cho điều luật trở nên khó hiểu và mâu thuẫn khi quy định rằng Việc sử dụng tác phẩm trong các trường hợp quy định tại khoản 1 Điều 25 của Luật Sở hữu trí tuệ không áp dụng đối với việc sao lại tác phẩm kiến trúc, tác phẩm tạo hình, chương trình máy tính ${ }^{35}$. Phải chăng quy định này muốn nói rằng không có bất kì hành vi sử dụng hạn chế nào có thể được áp dụng đối với chương trình máy tính?

\subsection{Bảo hộ chuơng trình máy tính bằng các co chế khác}

Bên cạnh cơ chế bảo hộ chương trình máy tính bằng các quy định của quyền tác giả, dường như luật Việt Nam không minh thị thừa nhận thêm bất kì cơ chế bảo hộ nào khác. Luật SHTT 2005 loại trừ chương trình máy tính ra khỏi danh mục các đối tượng có thể được cấp bằng sáng chế ${ }^{36}$. Có thể giải thích luật không coi chương trình máy tính là một giải pháp kĩ thuật. Hoặc luật cho rằng bản chất của chương trình máy tính là các phương pháp toán học thuần túy nên không thể được cấp bằng sáng chế $[15$, tr.33-42, 29]. Tuy nhiên, thực tiễn cho thấy dường như các cơ quan có thẩm quyền của Việt Nam vẫn chấp nhận cấp bằng sáng chế cho

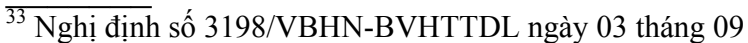
năm 2013, Điều 19a Khoản 3.

${ }^{34}$ Nghị định số $3198 /$ VBHN-BVHTTDL ngày 03 tháng 09 năm 2013, Điều 23 Khoản 5.

${ }^{35}$ Nghị định số 3198/VBHN-BVHTTDL ngày 03 tháng 09 năm 2013, Điều 24 Khoản 3.

${ }^{36}$ Luật sở hữu trí tuệ 2005, Điều 25 Khoản 2.
} 
chương trình máy tính trong một số trường hợp. Theo Quy chế thẩm định đơn đăng ký sáng chế của Cục SHTT Việt Nam "Mặc dù chương trình máy tính thuộc danh mục các đối tượng không được bảo hộ với danh nghĩa sáng chế nhưng nếu đối tượng yêu cầu bảo hộ có đặc tính kĩ thuật và thực sự là một giải pháp kĩ thuật, nhằm giải quyết một vấn đề kĩ thuật bằng một phương tiện kĩ thuật để tạo ra một hiệu quả kĩ thuật thì nó có thể được bảo hộ với danh nghĩa sáng chế" ${ }^{37}$. Ngoài ra, Cục SHTT đã chỉ rõ: "Trong trường hợp chương trình máy tính có khả năng được bảo hộ với danh nghĩa sáng chế như nêu trên, thì trong yêu cầu bảo hộ, các đối tượng có tên được thể hiện bằng cụm từ như "chương trình máy tính", "phần mềm máy tính", "sản phẩm chương trình/phần mềm máy tính", hoặc "tín hiệu mang chương trình", và các cụm từ tương đương khác là không được chấp nhận" ${ }^{\text {"38 }}$. Theo quy định này, có thể hiểu chương trình máy tính có thể được cấp bằng sáng chế nếu nó là một giải pháp được gắn với một phương tiện kĩ thuật tức là máy móc ở dạng vật thể $[15$, tr.33-42, 30]. Nếu đáp ứng tiêu chí này thì bằng sáng chế có thể được cấp cho các chương trình máy tính ở Việt $\mathrm{Nam}^{39}$.

Bên cạnh bằng sáng chế, theo quan điểm của tác giả chương trình máy tính còn có thể được bảo hộ với tư cách là đối tượng của bí mật kinh doanh. Theo luật Việt Nam bí mật kinh doanh là thông tin thu được từ hoạt động đầu tư tài chính, trí tuệ, chưa được bộc lộ và có khả năng sử dụng trong kinh doanh ${ }^{40}$. Theo định nghĩa này chương trình máy tính hoàn toàn có thể coi là thông tin thu được từ hoạt động đầu tư trí tuệ. Chỉ cần thông tin này đáp ứng các điều kiện đặt ra bởi Luật SHTT 2005 là có thể được bảo hộ, cụ thể là: (1) Không phải là hiểu biết thông thường và không dễ dàng có được;

\footnotetext{
${ }^{37}$ Quy chế thẩm định đơn đăng ký sáng chế (Ban hành kèm theo Quyết định số 487/QĐ-SHTT ngày 31/3/2010 của Cục trưởng Cục Sở hữu trí tuệ). Điều 5.8.2.5.

${ }^{38}$ Ibid.

${ }^{39}$ Ví dụ về các bằng sáng chế đã được cấp có thể xem thêm trong bài viết của PGS Trần Văn Hải đã dẫn ở trên.

${ }^{40}$ Luật sở hữu trí tuệ 2005, Điều 4 Khoản 23.
}

(2) Khi được sử dụng trong kinh doanh sẽ tạo cho người nắm giữ bí mật kinh doanh lợi thế so với người không nắm giữ hoặc không sử dụng bí mật kinh doanh đó; (3) Được chủ sở hữu bảo mật bằng các biện pháp cần thiết để bí mật kinh doanh đó không bị bộc lộ và không dễ dàng tiếp cận được ${ }^{41}$. Bí mật kinh doanh có lợi thế là bảo hộ tự động, trên cơ sở có được một cách hợp pháp bí mật kinh doanh và thực hiện việc bảo mật bí mật kinh doanh đó ${ }^{42}$. Chương trình máy tính cũng không nằm trong danh mục các đối tượng không được bảo hộ với danh nghĩa bí mật kinh doanh ${ }^{43}$.

\section{Thách thức đặt ra}

Tuy pháp luật Việt Nam bảo hộ chương trình máy tính với tư cách là một đối tượng của quyền tác giả, cụ thể là một tác phẩm văn học. Tuy nhiên, cơ chế bảo hộ này dường như vẫn còn đặt ra nhiều thách thức. Thực trạng bảo hộ chương trình máy tính ở Việt Nam cho thấy đây vẫn là đối tượng bị xâm phạm phổ biến nhất. Tình trạng sao chép, sử dụng chương trình máy tính trái phép diễn ra tràn lan. Điều này có thể bắt nguồn từ việc quyền tác giả chưa chắc đã là cơ chế bảo hộ phù hợp, thích ứng đối với chương trình máy tính. Có thể nêu ra một số thách thức như sau.

Thứ nhất, điều kiện bảo hộ quyền tác giả không hoàn toàn thích hợp khi áp dụng cho chương trình máy tính. Đặc biệt là tính nguyên gốc khi rất nhiều chương trình máy tính hiện nay được viết ra, sáng tạo dựa trên các mã nguồn mở đã có trước đó. Điều này vi phạm nguyên tắc không sao chép của tác phẩm $[15$, tr.33-42, 31].

Thứ hai, phạm vi bảo hộ chương trình máy tính chưa thật sự rõ ràng. Luật Việt Nam dường như chỉ bảo hộ mã nguồn và mã máy của chương trình vi tính. Thế còn toàn bộ cấu trúc của chương trình máy tính ví dụ như trình tự, tổ chức, menu lệnh, toàn bộ giao diện và cảm

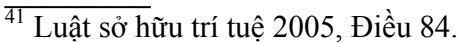

${ }^{42}$ Luật sở hữu trí tuệ 2005, Điều 6 Khoản 3 điểm c.

${ }^{43}$ Luật sở hữu trí tuệ 2005, Điều 85.
} 
nhận về chương trình (những yếu tố phi văn bản của mã nguồn) thì có được bảo hộ không? [18, tr.408] Việt Nam cũng chưa có sự phân loại chương trình máy tính thành các loại như hệ điều hành, phần mềm lập trình, phần mềm ứng dụng dù các chương trình này có chức năng, mục tiêu khá là khác biệt nhau.

Thứ ba, thời hạn bảo hộ quyền tác giả đối với chương trình máy tính là bất hợp lí. Hiện nay Việt Nam đang áp dụng thời hạn bảo hộ quyền tác giả chung cho chương trình máy tính. Đây là thời gian quá dài nếu tính đến vòng đời sản phẩm của một chương trình máy tính. Điều này có thể dẫn đến việc hạn chế cạnh tranh, tiếp cận thông tin từ đó hạn chế sức sáng tạo [32].

Thứ tư, các quy định hiện nay về sử dụng hạn chế đối với chương trình máy tính tỏ ra là thiếu hợp lí. Một số hành vi sử dụng hạn chế quan trọng, được pháp luật nhiều nước quy định nhưng luật Việt Nam lại chưa thừa nhận. Ví dụ như hành vi quan sát, nghiên cứu và thử nghiệm chức năng của một chương trình máy tính [33]. Hay hành vi decompilation - phân tích ngược một chương trình máy tính [33].

Thứ năm, với sự phát triển và tác động mạnh mẽ của môi trường internet, không gian ảo, việc bảo hộ chương trình máy tính càng trở nên khó khăn và phức tạp. Tuy nhiên, các quy định của pháp luật Việt Nam dường như vẫn chỉ dự liệu cho môi trường tương tự - analogue [34].

Vì những thách thức đặt ra đối với việc bảo hộ chương trình máy tính như là một đối tượng của quyền tác giả như trên, nên các chuyên gia trong nước và quốc tế vẫn đang cần phải và tiếp tục thảo luận để tìm kiếm một giải pháp thích hợp hơn [35].

\section{Tài liệu tham khảo}

[1] Stair, Ralph M. và đồng nghiệp, Principles of Information Systems, Sixth Edition. Thomson Learning, Inc, 2003, trang 132.

[2] Commission of European Communities (2000), Report from the Commission to the Council, the European Parliament and the Economic and Social Committee on the implementation and effects of Directive 91/250/EEC on the legal protection of computer programs, trang 9.

[3] Regulations on Computers Software Protection promulgated by Decree No. 339 of the State Council of the People's Republic of China on December 20, 2001, Điều 3 Khoản 1: "computer program" means a coded instruction sequence which may be executed by devices with information processing capabilities such as computers, or a symbolic instruction sequence or symbolic statement sequence which may be automatically converted into a coded instruction sequence for the purpose of obtaining certain expected results; the source program and object program of a computer program shall be deemed as one and the same work.

[4] Roy A. Allan, A Bibliography of the Personal Computer [electronic Resource]: the Books and Periodical Articles, Allan Publishing - 2006, trang 73.

[5] The Software and Information Technology Services Industry in the United States (truy cập ngày 22/11/2018) tại https://www.selectusa.gov/software-andinformation-technology-services-industryunited-states.

[6] Gartner Says Worldwide Software Market Grew 4.8 Percent in 2013 (truy cập ngày 22/11/2018) tại http://www.gartner.com/newsroom/id/2696317.

[7] Vân Ly, Doanh thu phần mềm và dịch vụ CNTT tăng gấp rưỡi sau 5 năm (truy cập ngày 22/11/2018)

http://www.thesaigontimes.vn/145478/Doanhthu-phan-mem-va-dich-vu-CNTT-tang-gapruoi-sau-5-nam.html.

[8] Britney Fitzgerald, Software Piracy: Study Claims 57 Percent Of The World Pirates Software (VIDEO) (truy cập ngày 22/11/2018) tại http://www.huffingtonpost.com/2012/06/01/sof tware-piracy-study-bsa_n_1563006.html.

[9] Shadow Market of Pirated Software Grows to $\$ 63$ Billion (truy cập ngày 22/11/2018) tại http://globalstudy.bsa.org/2011/.

[10] BSA, News Release (truy cập ngày 22/11/2018) http://globalstudy.bsa.org/2011/downloads/press/p r_vietnam_en.pdf.

[11] WIPO, International IP Protection of Software, tại http://www.wipo.int/edocs/mdocs/copyright/en/wi po_ip_cm_07/wipo_ip_cm_07_www_82573.doc.

[12] Commission of European Communities (2000), tldd, trang 5.

[13] WIPO Model Provisions on the Protection of Computer Programs (1978) prepared by the 
International Bureau of the World Intellectual Property Organization tai ftp://ftp.wipo.int/pub/library/ebooks/wipopublic ations/wipo_pub_814(e).pdf.

[14] John C. Phillips, Sui generis intellectual property protection for computer software (1992) George Washington Law Review tại https://cyber.harvard.edu/property/protection/re sources/phillips_unedited.html.

[15] Trần Văn Hải, Bảo hộ chương trình máy tính như đối tượng độc lập của quyền sở hữu trí tuệ, Tạp chí Nhà nước và Pháp luật, 11 (295) (2012) trang 33-42.

[16] WIPO, International IP Protection of Software, tại http://www.wipo.int/edocs/mdocs/copyright/en/wi po_ip_cm_07/wipo_ip_cm_07_www_82573.doc.

[17] Commission of European Communities (2000), tldd; Xem Council Directive 91/250/EEC of 14 May 1991 on the legal protection of computer programs..

[18] Agreement on trade-related aspects of intellectual property rights, Điều 10 Khoản 1 .

[19] WIPO Copyright Treaty, Điều 4.

[20] Nguyen Ngoc Xuan Thao, Intellectual property law: cases, materials and problems, VNUHCM publishing house, Ho Chi Minh city, 2013, trang $408-409$.

[21] Kretschmer, Martin, Software as Text and Machine: The Legal Capture of Digital Innovation , Journal of Information Law \& Technology (JILT), Centre for Intellectual Property Policy and Management, Bournemouth University, 4 July 2003.

[22] In re Bilski,, 545 F.3d 943 (Fed.Cir.2008); Nguyen Ngoc Xuan Thao, tldd, trang 409.

[23] Agreement on trade-related aspects of intellectual property rights.

[24] Software Patents in Europe, Chairman's Opening Remarks, Speaker: Paul Hartnack, Comptroller General, The Patent Office, Last updated 6 December 2000 (Archive.org).

[25] The European Paten Convention, Điều 52 Khoản 1.
[26] Paten Cooperation Treaty (1970) Rules 39.1 và Rule 67.1.

[27] Data General Corp.v. Grumman Systems Support Corp ., 825 F. Supp. 340 (D. Mass. 1993).

[28] Lê Nết \& Nguyễn Xuân Quang (chủ biên), Giáo trình luật sở hữu trí tuệ (tái bản có bổ sung),Nhà xuất bản Hồng Đức, Hà Nội, 2016. trang 51.

[29] Lee B. Burgunder, Legal aspects of managing technology, $2^{\text {nd }}$ ed, West legal studies in business, 2001. trang 239 - 297.

[30] Lê Nết, Quyền sở hữu trí tuệ (tài liệu bài giảng) (Nhà xuất bản đại học quốc gia thành phố Hồ Chí Minh 2006) trang 15 - 19.

[31] Nguyễn Đình Huy, 'Một vài suy nghĩ về bảo hộ phần mềm máy tính ở Việt Nam' (2002) 8 Tạp chí Khoa học Pháp lí tại http://www.hcmulaw.edu.vn/hcmulaw/index.php? option $=$ com_content\&view $=$ article\&id $=198:$ tc 200 2so4mssnvbhpm\&catid=90: $\operatorname{ctc} 20024 \&$ Itemid $=64$

[32] Commission of European Communities (2000), Report from the Commission to the Council, the European Parliament and the Economic and Social Committee on the implementation and effects of Directive 91/250/EEC on the legal protection of computer programs, trang 13.

[33] Nguyễn Thị Hồng Nhung, Quyền tác giả trong không gian ảo, Nhà xuất bản Đại học Quốc gia thành phố Hồ Chí Minh, Hồ Chí Mih, 2015.

[34] Nguyễn Vân Anh và các tác giả khác, Giải mã công nghệ đối với chương trình máy tính, Tạp chí hoạt động khoa học, (2012) 633, tại https://thongtinphapluatdansu.edu.vn/2012/04/24/ gi $\%$ E1\%BA\%A3i-m-cng-ngh $\%$ E1\%BB $\% 87$ $\mathrm{d} \% \mathrm{E} 1 \% \mathrm{BB} \% 91 \mathrm{i}-\mathrm{v} \% \mathrm{E} 1 \% \mathrm{BB} \% 9 \mathrm{Bi}-$ ch $\%$ C6\%B0\%C6\%A1ng-trnh-my-tnh/.

[35] Trần Văn Hải, 'Chương trình máy tính nên được bảo hộ là đối tượng nào của quyền sở hữu trí tuệ' (2009) 597 Tạp chí hoạt động khoa học tại https://thongtinphapluatdansu.edu.vn/2009/11/12/ 4041. 


\title{
Computer Program Protection in Vietnamese Law: Practices and Challenges
}

\author{
Tran Kien
}

VNU School of Law, 144 Xuan Thuy, Cau Giay, Hanoi, Vietnam

\begin{abstract}
This article analyzes the provions governing computer program protection in Vietnam. It argues that Vietnam has learnt from foreign law and practice in governing computer program as a work of authorship. However, authors' rights protection has its own limits, loopholes that at times hinder the effective protection of computer program. It is thus necessary to re-think the current approach or look for a better legal model, a mechanism of protection that better governs computer program in Vietnam.
\end{abstract}

Keywords: Computer program, authors' rights, patent, contract, intellectual property law. 